PHILOSOPHICAL

TRANSACTIONS A

royalsocietypublishing.org/journal/rsta

\section{Research}

Cite this article: Coates $\mathrm{CS}$, Gray HJ, Bulled

JM, Boström HLB, Simonov A, Goodwin AL.

2019 Ferroic multipolar order and disorder in

cyanoelpasolite molecular perovskites. Phil.

Trans. R. Soc. A 377: 20180219.

http://dx.doi.org/10.1098/rsta.2018.0219

Accepted: 22 February 2019

One contribution of 10 to a theme issue

'Mineralomimesis: natural and synthetic

frameworks in science and technology'.

\section{Subject Areas:}

inorganic chemistry, statistical physics, chemical physics

\section{Keywords:}

mineralomimesis, hybrid perovskites,

multipolar order, phase transitions

\section{Author for correspondence:}

\section{A. L. Goodwin}

e-mail: andrew.goodwin@chem.ox.ac.uk

Electronic supplementary material is available online at https://dx.doi.org/10.6084/m9.

figshare.c.4472432.

\section{THE ROYAL SOCIETY

\title{
Ferroic multipolar order and disorder in cyanoelpasolite molecular perovskites
}

C. S. Coates ${ }^{1}$, H. J. Gray ${ }^{1}$, J. M. Bulled',

\section{H. L. B. Boström ${ }^{2}$, A. Simonov ${ }^{1}$ and A. L. Goodwin ${ }^{1}$}

${ }^{1}$ Inorganic Chemistry Laboratory, South Parks Road, 0xford OX13QR, UK

${ }^{2}$ Department of Chemistry, Uppsala University, P0 Box 256, SE-751 05, Uppsala, Sweden

ALG, 0000-0001-9231-3749

We use a combination of variable-temperature highresolution synchrotron X-ray powder diffraction measurements and Monte Carlo simulations to characterize the evolution of two different types of ferroic multipolar order in a series of cyanoelpasolite molecular perovskites. We show that ferroquadrupolar order in $\left[\mathrm{C}_{3} \mathrm{~N}_{2} \mathrm{H}_{5}\right]_{2} \mathrm{Rb}\left[\mathrm{Co}(\mathrm{CN})_{6}\right]$ is a first-order process that is well described by a fourstate Potts model on the simple cubic lattice. Likewise, ferrooctupolar order in $\left[\mathrm{NMe}_{4}\right]_{2} \mathrm{~B}\left[\mathrm{Co}(\mathrm{CN})_{6}\right](\mathrm{B}=\mathrm{K}$, $\mathrm{Rb}, \mathrm{Cs}$ ) also emerges via a first-order transition that now corresponds to a six-state Potts model. Hence, for these particular cases, the dominant symmetry breaking mechanisms are well understood in terms of simple statistical mechanical models. By varying composition, we find that the effective coupling between multipolar degrees of freedom-and hence the temperature at which ferromultipolar order emerges-can be tuned in a chemically sensible manner.

This article is part of the theme issue 'Mineralomimesis: natural and synthetic frameworks in science and technology'.

\section{Introduction}

Ferroic order in framework materials is implicated in a wide range of functional responses, including ferroelectricity, ferromagnetism and ferroelasticity [1-3]. In each case, crystal symmetry is broken by the coalignment of a particular type of internal degree of freedom: whether it is the dipolar displacements of ferroelectrics, the orientation of magnetic moments in 
ferromagnets, or the geometric strains of ferroelastics. Of particular currency is the concept of linking different types of ferroic order to give multiferroic materials; for example, a system in which magnetization might be inverted by application of an electric field [4-6]. Because of the strong functional implications of multiferroicity, there is intense interest in developing a thorough understanding of the chemical and physical design rules for intentionally introducing particular types of ferroic order into materials. In the particular context of inorganic perovskites, notable examples include the concept of 'tilt engineering' [7,8], the exploitation of second-order JahnTeller effects [9], and the Goodenough-Kanamori rules for magnetic exchange [10-12].

This is a special issue on the topic of mineralomimesis, and so it is perhaps a natural place to question whether similar strategies might be important for molecular mimics of conventional perovskites. Molecular perovskites are systems for which at least one component of the nominal $\mathrm{ABX}_{3}$ composition is molecular in nature [13-16], with ferroic order usually involving coalignment of polar A-site cations $[17,18]$. In transition metal formates (e.g. $\left[\left(\mathrm{CH}_{3}\right)_{2} \mathrm{NH}_{2}\right]$ $\mathrm{Mn}(\mathrm{HCOO})_{3}$ [19-21]), this type of ferrodipolar order is known sometimes to coexist with (anti)ferromagnetism to give a form of multiferroic response [19]. The exploitation of glassy dynamics can lead to relaxor-like behaviour in related systems [22]. And in the halide photovoltaics (e.g. $\left[\mathrm{CH}_{3} \mathrm{NH}_{3}\right] \mathrm{PbI}_{3}$ [23]), local dipolar order is implicated in exciton stabilization $[24,25]$. So there is again a clear link to function, but the development of design rules for controlling ferroic order still remains a significant and important challenge in this emerging field $[16,26,27]$. Moreover, one expects some differences in microscopic mechanisms relative to conventional perovskites: for example, any ferroelectric transition must be order-disorder in nature for molecular perovskites, whereas such transitions are often displacive for their inorganic parents [28-30].

One other fundamental difference between molecular and conventional perovskites-and the focus of our study-is the role of molecular shape in imparting additional orientational degrees of freedom that themselves might give rise to new types of ferroic order [31-33]. What happens when the A-site cation of a molecular perovskite is flat but non-polar, for example? Its orientation is then described formally by a quadrupole rather than by a vector, and one can envisage the possibility of ferroic order involving these quadrupoles [34,35]. This is precisely what happens in guanidinium formate perovskites, where ferroic quadrupole order even has a particular functional consequence. The interplay of collective $\mathrm{Cu}^{2+} \mathrm{Jahn}$ Teller distortions with ferroquadrupolar order in $\left[\left(\mathrm{C}(\mathrm{NH})_{2}\right)_{3}\right] \mathrm{Cu}(\mathrm{HCOO})_{3}$ drives inversion symmetry breaking via a so-called hybrid improper ferroelectric mechanism [36-38]. Indeed the various possible types of multipolar order that are more generally accessible to molecular perovskites seem to be particularly useful ingredients for generating polar (and, in turn, ferroelectric) phases [39]. Consequently, we are interested to understand more deeply the phenomenology of multipolar order in molecular perovskites-not only because it might be exploited is this functional materials design sense, but also because of the conceptual parallel to problems in exotic 'hidden order' systems such as $\mathrm{URu}_{2} \mathrm{Si}_{2}$ [40] and $\mathrm{Gd}_{3} \mathrm{Ga}_{5} \mathrm{O}_{12}$ [41].

Here, we use variable-temperature high-resolution synchrotron X-ray powder diffraction measurements to characterize the evolution of two different types of ferroic multipolar order in a series of cyanoelpasolite molecular perovskites. We supplement these experimental measurements with Monte Carlo calculations, inspired by recent studies of hybrid perovskites $[42,43]$. In this way, we show that ferroquadrupolar order in $\left[\mathrm{C}_{3} \mathrm{~N}_{2} \mathrm{H}_{5}\right]_{2} \mathrm{Rb}\left[\mathrm{Co}(\mathrm{CN})_{6}\right]$ is a firstorder process that is well described by a four-state Potts model on the simple cubic lattice. Likewise, ferrooctupolar order in $\left[\mathrm{NMe}_{4}\right]_{2} \mathrm{~B}\left[\mathrm{Co}(\mathrm{CN})_{6}\right](\mathrm{B}=\mathrm{K}, \mathrm{Rb}, \mathrm{Cs})$ also emerges via a firstorder transition that now corresponds to a six-state Potts model. So, for these particular cases, the dominant symmetry-breaking mechanisms are well understood in terms of simple statistical mechanical models. By varying composition, we find that the effective coupling between multipolar degrees of freedom-and hence the temperature at which ferromultipolar order emerges-can be tuned in a chemically sensible manner.

Our paper is arranged as follows. We begin with a brief survey of the crystal symmetry of the cyanoelpasolite family, and describe the group theoretical implications of multipolar order 
for the various systems we proceed to study experimentally. In $\S 3$, we describe the various methodologies used in our study, before proceeding in $\$ 4$ to present our main findings. We take each of our two key systems in turn: $\left[\mathrm{C}_{3} \mathrm{~N}_{2} \mathrm{H}_{5}\right]_{2} \mathrm{Rb}\left[\mathrm{Co}(\mathrm{CN})_{6}\right]$ then $\left[\mathrm{NMe}_{4}\right]_{2} \mathrm{~B}\left[\mathrm{Co}(\mathrm{CN})_{6}\right]$ $(\mathrm{B}=\mathrm{K}, \mathrm{Rb}, \mathrm{Cs})$. Our paper concludes with a discussion regarding the potential for controlling and exploiting ferroic multipolar order in molecular frameworks.

\section{Theory}

Cyanoelpasolites are molecular analogues of double perovskites. In both cases, the parent structure has cubic $F m \overline{3} m$ crystal symmetry and general formula $\mathrm{A}_{2} \mathrm{~B}\left[\mathrm{~B}^{\prime} \mathrm{X}_{6}\right]$. It is the rocksalt ordering of $\mathrm{B}$ and $\mathrm{B}^{\prime}$ ions that is responsible for face-centring. Cyanoelpasolites correspond to the specific case for which $\mathrm{X}=\mathrm{CN}^{-}$(elpasolites themselves are the corresponding fluorides). In most cases, the A-site is occupied by a monovalent organic cation, such as imidazolium or tetramethylammonium $[31,35,44]$. The $B$ and $\mathrm{B}^{\prime}$ sites are often occupied by group 1 and transitionmetal cations, respectively; in any case, the total charge on these two species sums to four.

Our concern in this particular study is with multipolar order of the molecular A-site cations. In the $F m \overline{3} m$ aristotype, the point symmetry of the A-site is $T_{d}$ (Wyckoff position $8 c$; figure $1 a$ ). The aristotypic structure is known to occur experimentally in two cases. If the point-group symmetry of the A-site cation is a supergroup of $T_{d}$, as is the case in $\mathrm{Cs}_{2} \mathrm{Mn}\left[\mathrm{Mn}(\mathrm{CN})_{6}\right]$, there may be no driving force for symmetry breaking. Alternatively, if a lower-symmetry Asite cation is statistically disordered over multiple equivalent orientations, then this disordered (presumably high-temperature) state may also have $F m \overline{3} m$ symmetry. This second case is realized at temperatures above $423 \mathrm{~K}$ in $\left[\mathrm{CH}_{3} \mathrm{NH}_{3}\right] \mathrm{K}\left[\mathrm{Co}(\mathrm{CN})_{6}\right]$, for example $[35,45]$. By contrast to these two scenarios, multipolar order involves long-range symmetry lowering at the A-site to a (proper) subgroup of $T_{d}$.

The first family of cyanoelpasolites we study in this context of multipolar order is based on $\left[\mathrm{C}_{3} \mathrm{~N}_{2} \mathrm{H}_{5}\right]_{2} \mathrm{Rb}\left[\mathrm{Co}(\mathrm{CN})_{6}\right]$; we are interested in orientational order of the imidazolium A-site cations. As it happens, there are two independent components to this orientational order, but we are concerned here only with the higher-energy term: namely the selection of a plane in which the imidazolium ion sits. This is physically relevant because at ambient temperature the imidazolium ions in $\left[\mathrm{C}_{3} \mathrm{~N}_{2} \mathrm{H}_{5}\right]_{2} \mathrm{Rb}\left[\mathrm{Co}(\mathrm{CN})_{6}\right]$ are constrained to lie within a single set of planes, but they retain rotational freedom within these planes. This type of order corresponds to lowering of the point symmetry at the A-site from $T_{d}$ to $C_{3 v}$ (figure $1 b$ ), and is characterized by the $T_{2}$ irreducible representation (irrep). It corresponds to quadrupolar order because the $x y, x z, y z$ quadrupoles also transform with this symmetry. Consequently, we can identify the local orientation of a given imidazolium ion with a unit quadrupole of the (tensorial) form

$$
\mathbf{Q}=\frac{1}{\sqrt{6}}\left[\begin{array}{ccc}
0 & e_{1} e_{2} & e_{1} e_{3} \\
e_{1} e_{2} & 0 & e_{2} e_{3} \\
e_{1} e_{3} & e_{2} e_{3} & 0
\end{array}\right]
$$

where $e_{i}$ are the Cartesian components of the vectors $\mathbf{e} \in\langle 111\rangle$. There are four distinct values of $\mathbf{Q}$, which correspond to the four body diagonals of the cubic void. The existence of these four states is consistent with the ratio of the orders of the point groups $T_{d}$ and $C_{3 v}$.

The second family of cyanoelpasolites is based on a different A-site cation: namely, tetramethylammonium. We will come to show that orientational order within the family $\left[\mathrm{NMe}_{4}\right]_{2} \mathrm{~B}\left[\mathrm{Co}(\mathrm{CN})_{6}\right](\mathrm{B}=\mathrm{K}, \mathrm{Rb}, \mathrm{Cs})$ involves correlated rotation of the $\mathrm{NMe}_{4}$ ions around a local $\langle 100\rangle$ axis. Such a rotation has the effect of reducing the local point symmetry from $T_{d}$ to $S_{4}$, and is characterized by the $T_{1}$ irrep (figure $1 c$ ). This distortion now corresponds to octupolar order because the $x\left(z^{2}-y^{2}\right), y\left(z^{2}-x^{2}\right), z\left(x^{2}-y^{2}\right)$ octupoles also transform with this symmetry. For ease of representation, we will identify each local state by a unit axial vector $\mathbf{e} \in\langle 100\rangle .{ }^{1}$ There are six such states, as given by the ratio of the orders of the point groups $T_{d}$ and $S_{4}$. The meaning of each

\footnotetext{
${ }^{1}$ One might equally well have used a set of six rank-three tensors, with equivalent results.
} 
(a)
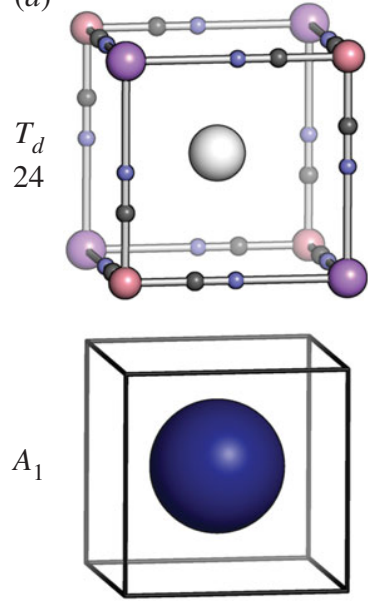

(b)
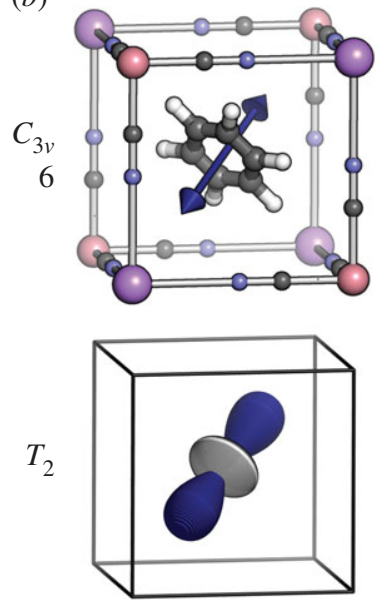

(c)

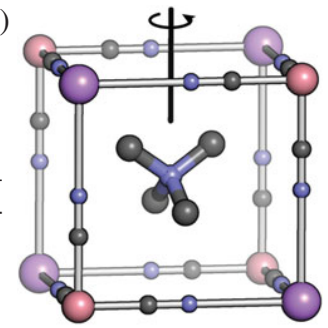

4

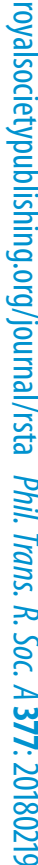

Figure 1. A cube of the cyanoelpasolite structure $\mathrm{A}_{2} \mathrm{~K}\left[\mathrm{Co}(\mathrm{CN})_{6}\right]$, with the multipolar A-site cations in this study. The relevant point group and its order are indicated, and the corresponding irrep shown below. The site symmetry of the A-site is $(a) T_{d}$ if $A$ is a metal or if a lower symmetry A-site cation is statistically disordered over multiple orientations. (b) The $\left[\mathrm{C}_{3} \mathrm{~N}_{2} \mathrm{H}_{5}\right]^{+}$ion has rotational freedom about the $\langle 111\rangle$ axis, and so can be represented as a quadrupole which transforms as the $T_{2}$ irrep. The presence of a three-fold axis means that crystallographically the five-membered imidazolate ring appears as if it has six atoms [49]. (c) The octupolar order of $\mathrm{NMe}_{4}{ }^{+}$ions corresponds to concerted rotations about a given $\langle 100\rangle$ axis, characterized by the $T_{1}$ irrep, which lowers the point symmetry to $\mathrm{S}_{4}$. Co is shown in pink, $\mathrm{K}$ in purple, $\mathrm{C}$ in grey, $\mathrm{N}$ in blue and $\mathrm{H}$ in white (H atoms are omitted from $\mathrm{NMe}_{4}{ }^{+}$for clarity).

e can be taken as the orientation of the axis about which a given $\mathrm{NMe}_{4}^{+}$cation is rotated in an anticlockwise sense (figure 1).

Having identified these local multipolar degrees of freedom in our two cyanoelpasolite families-as captured by quadrupoles $\mathbf{Q}$ or by axial vectors $\mathbf{e}-$ we will assess in due course the extent to which phase transitions observed experimentally in these systems can be understood in terms of simple models of ferroic multipolar order and disorder.

\section{Methods}

\section{(a) Synthesis}

$\mathrm{A}_{2} \mathrm{~K}\left[\mathrm{Co}(\mathrm{CN})_{6}\right]\left(\mathrm{A}=\mathrm{NMe}_{4}^{+}, \mathrm{C}_{3} \mathrm{~N}_{2} \mathrm{H}_{5}^{+}\right)$was synthesized using the method outlined in [31]. Slow evaporation of aqueous solutions of $\mathrm{K}_{3} \mathrm{Co}(\mathrm{CN})_{6}(0.1 \mathrm{mmol}, 5 \mathrm{ml})$ and $\left[\mathrm{C}_{3} \mathrm{~N}_{2} \mathrm{H}_{5}\right] \mathrm{Cl}(0.2 \mathrm{mmol}, 5 \mathrm{ml})$ yielded a mixture of $\left[\mathrm{C}_{3} \mathrm{~N}_{2} \mathrm{H}_{5}\right]_{2} \mathrm{~K}\left[\mathrm{Co}(\mathrm{CN})_{6}\right]$ and $\mathrm{KCl}$ according to the following equation:

$$
\mathrm{K}_{3} \mathrm{Co}(\mathrm{CN})_{6(\mathrm{aq})}+2\left[\mathrm{C}_{3} \mathrm{~N}_{2} \mathrm{H}_{5}\right] \mathrm{Cl}_{(\mathrm{aq})} \rightarrow\left[\mathrm{C}_{3} \mathrm{~N}_{2} \mathrm{H}_{5}\right]_{2} \mathrm{~K}\left[\mathrm{Co}(\mathrm{CN})_{6}\right]_{(\mathrm{aq})}+2 \mathrm{KCl}_{(\mathrm{aq})} .
$$

$\left[\mathrm{NMe}_{4}\right]_{2} \mathrm{~K}\left[\mathrm{Co}(\mathrm{CN})_{6}\right]$ was synthesized using the same approach, but employing $\mathrm{NMe}_{4} \mathrm{Cl}$ instead of $\left[\mathrm{C}_{3} \mathrm{~N}_{2} \mathrm{H}_{5}\right] \mathrm{Cl}$.

The alkali-metal-substituted products $\mathrm{A}_{2} \mathrm{~B}\left[\mathrm{Co}(\mathrm{CN})_{6}\right]$ were synthesized via slow evaporation of aqueous solutions of $\mathrm{H}_{3} \mathrm{Co}(\mathrm{CN})_{6}$ (synthesis outlined below), with the relevant hydroxide $\mathrm{BOH} \cdot x \mathrm{H}_{2} \mathrm{O}$ and molecular cationic chloride $\mathrm{ACl} .\left[\mathrm{C}_{3} \mathrm{~N}_{2} \mathrm{H}_{5}\right]_{2} \mathrm{Rb}\left[\mathrm{Co}(\mathrm{CN})_{6}\right]$, for example, was synthesized via slow evaporation of aqueous solutions of $\mathrm{H}_{3} \mathrm{Co}(\mathrm{CN})_{6}(0.1 \mathrm{mmol}, 5 \mathrm{ml}), \mathrm{RbOH}$. $x \mathrm{H}_{2} \mathrm{O}(0.3 \mathrm{mmol}, 1 \mathrm{ml})$ and $\left[\mathrm{C}_{3} \mathrm{~N}_{2} \mathrm{H}_{5}\right] \mathrm{Cl}(0.2 \mathrm{mmol}, 5 \mathrm{ml})$ :

$$
\mathrm{H}_{3} \mathrm{Co}(\mathrm{CN})_{6(\mathrm{aq})}+2\left[\mathrm{C}_{3} \mathrm{~N}_{2} \mathrm{H}_{5}\right] \mathrm{Cl}_{(\mathrm{aq})}+3 \mathrm{RbOH} \cdot x \mathrm{H}_{2} \mathrm{O}_{(\mathrm{aq})}
$$


In all cases, yields were approximately $100 \mathrm{mg}$, and samples were obtained as offwhite fine powders. Sample composition was confirmed using single-crystal X-ray diffraction measurements.

\section{(b) Synthesis of $\mathrm{H}_{3} \mathrm{Co}(\mathrm{CN})_{6}$}

$\mathrm{H}_{3} \mathrm{Co}(\mathrm{CN})_{6}$ was synthesized via ion-exchange of an aqueous solution of $\mathrm{K}_{3} \mathrm{Co}(\mathrm{CN})_{6}$ with a concentrated solution of $\mathrm{H}_{2} \mathrm{SO}_{4}$ [46]. The ion-exchange column was loaded with $100 \mathrm{~g}$ of Dowex ${ }^{\circledR}$ $50 \mathrm{WX} 8$ hydrogen form ion exchange resin and rinsed thoroughly with distilled water. The column was regenerated by passing through a solution of $2 \mathrm{M} \mathrm{H}_{2} \mathrm{SO}_{4}$. An aqueous solution of $\mathrm{K}_{3} \mathrm{Co}(\mathrm{CN})_{6}$ $(2 \mathrm{~g}, 50 \mathrm{ml})$ was passed through the column followed by $100 \mathrm{ml}$ of distilled water and the eluent collected. The volume of the eluent was reduced by evaporation of the solvent. The column was then regenerated with $\mathrm{H}^{+}$and the process repeated three times. The dry product was then characterized as pure $\mathrm{H}_{3} \mathrm{Co}(\mathrm{CN})_{6}$ using in-house X-ray powder diffraction measurements (see electronic supplementary material for more details).

\section{(c) Powder X-ray diffraction}

Variable temperature powder synchrotron X-ray diffraction measurements patterns were collected using the I11 beamline at the Diamond Light Source (UK). Individual datasets were collected using a Mythen2 Position Sensitive Detector (PSD) with two 2-second scans separated by an angular shift in detector position of $2.5^{\circ}$. The wavelength and intrinsic peak shape parameters were determined by refinement of a diffraction pattern collected from a known Si NIST 640c standard. The X-ray wavelength used was $\lambda=0.82592 \AA$. The samples were heated at a rate of $6 \mathrm{~K} \mathrm{~min}^{-1}$ using an Oxford Cryostreams attachment and data collected over the temperature ranges $200-400 \mathrm{~K}, 300-400 \mathrm{~K}$ or $400-500 \mathrm{~K}$.

Lattice parameters were obtained via batch Pawley refinements using TOPAS academic [47]. For $\left[\mathrm{C}_{3} \mathrm{~N}_{2} \mathrm{H}_{5}\right]_{2} \mathrm{Rb}\left[\mathrm{Co}(\mathrm{CN})_{6}\right]$, the intensity profiles for the rhombohedral and cubic phases were refined at 400 and $500 \mathrm{~K}$, respectively; these were then fixed and a scale factor refined for each (the intensity profile for $\mathrm{KCl}$ was refined at $400 \mathrm{~K}$ ). Three batch refinements were employed: the first refined the scale factor of the $R \overline{3} \mathrm{~m}$ phase $(400-458 \mathrm{~K})$; the second refined the scale factors of both the $R \overline{3} m$ and $F m \overline{3} m$ phases $(458-480 \mathrm{~K})$; and the final phase refined only that of the $F m \overline{3} m$ phase. The resulting normalized lattice parameters where $a_{C} \sim \sqrt{2} a_{R} \sim\left(c_{R} / \sqrt{3}\right)$ from each of these protocols is shown in figure $3 b$ in red, orange and green, respectively. The errors were all smaller than the data points.

A similar protocol was used for $\left[\mathrm{NMe}_{4}\right]_{2} \mathrm{~B}\left[\mathrm{Co}(\mathrm{CN})_{6}\right](\mathrm{B}=\mathrm{K}, \mathrm{Rb}, \mathrm{Cs})$. For $\mathrm{B}=\mathrm{K}, \mathrm{Rb}$, the intensity profile for the $I 4 / m$ phase was refined at $300 \mathrm{~K}$ and $250 \mathrm{~K}$ respectively. Scale factors for the different phases were then refined for (i) $I 4 / m$ only, (ii) $I 4 / m$ and $F m \overline{3} m$ and (iii) $F m \overline{3} m$ only, in the temperature ranges (i) 300-367, (ii) 367-371, (iii) 371-400 $\mathrm{K}$ for $\mathrm{B}=\mathrm{K}$ and (i) $250-321$, (ii) 321-330 and (iii) $330-400 \mathrm{~K}$ for $\mathrm{B}=\mathrm{Rb}$. The refined normalized lattice parameters where $a_{\mathrm{C}} \sim \sqrt{2} a_{\mathrm{T}} \sim \mathcal{c}_{\mathrm{T}}$ from each of these protocols is shown in figure $5 b$ in red, orange and green, respectively, for $\mathrm{B}=\mathrm{K}$. For $\mathrm{B}=\mathrm{Cs}$ the variation of the $I 2 / m(250-302 \mathrm{~K})$ and $F m \overline{3} m(302-400 \mathrm{~K})$ phases were refined independently.

\section{(d) Monte Carlo simulations}

In order to model the coupling between multipolar or rotational degrees of freedom for these order-disorder phase transitions, we carried out Metropolis Monte Carlo simulations using a custom-written code related to that reported in [41]. We used a primitive cubic lattice of $10 \times$ $10 \times 10$ sites, subject to periodic boundary conditions. Depending on the particular simulation concerned, each site was decorated with an appropriate $n$-state Potts variable [48]. Configurations were initialized using random states. The configurational energy was calculated as described in the relevant sections of the text below. Moves were proposed at random and accepted subject 
to the Metropolis Monte Carlo criterion. Simulations were carried out for unit coupling constant $J$. The initial temperature was $6 \mathrm{~J}$. Each simulation was allowed to proceed until equilibration (approx. $5 \times 10^{5}$ state changes). Successive simulations involved a reduction in temperature of $0.01 \mathrm{~J}$. The entire simulation process was repeated five times for each model.

\section{Results}

\section{(a) Ferroquadrupolar order in $\left[\mathrm{C}_{3} \mathrm{~N}_{2} \mathrm{H}_{5}\right]_{2} \mathrm{Rb}\left[\mathrm{Co}(\mathrm{CN})_{6}\right]$}

Our study begins by characterizing orientational order in $\left[\mathrm{C}_{3} \mathrm{~N}_{2} \mathrm{H}_{5}\right]_{2} \mathrm{Rb}\left[\mathrm{Co}(\mathrm{CN})_{6}\right]$. To the best of our knowledge, this particular system has not previously been reported, but the closely related materials $\left[\mathrm{C}_{3} \mathrm{~N}_{2} \mathrm{H}_{5}\right]_{2} \mathrm{~K}\left[\mathrm{Co}(\mathrm{CN})_{6}\right]$ and $\left[\mathrm{C}_{3} \mathrm{~N}_{2} \mathrm{H}_{5}\right]_{2} \mathrm{~K}\left[\mathrm{Fe}(\mathrm{CN})_{6}\right]$ have been described in [31,49]. The ambient-temperature structures of these phases have rhombohedral $R \overline{3} m$ symmetry, in which each imidazolium ion is constrained to lie within a set of parallel planes. In the context of the quadrupolar states of equation (2.1), this phase corresponds to ferroquadrupolar order. To a large extent, the focus of these earlier studies has been the evolution of dipolar order on cooling from room temperature, which is associated with an anomaly in the corresponding dielectric response $[31,49,50]$. While the imidazolium cations are free to rotate (within their confined plane) in the ambient $R \overline{3} m$ phase, in this low-temperature state, each cation adopts a single orientation. Working in the other direction, it is not yet known whether it is possible to disorder the quadrupolar degrees by heating the material; in other words, to drive the ambient ferroquadrupolar phase into a paraquadrupolar state.

The synchrotron powder X-ray diffraction pattern of our $\left[\mathrm{C}_{3} \mathrm{~N}_{2} \mathrm{H}_{5}\right]_{2} \mathrm{Rb}\left[\mathrm{Co}(\mathrm{CN})_{6}\right]$ sample at $400 \mathrm{~K}$ is shown in figure $2 a$. We were able to index this pattern in terms of a rhombohedral unit cell of comparable size to that of $\left[\mathrm{C}_{3} \mathrm{~N}_{2} \mathrm{H}_{5}\right]_{2} \mathrm{~K}\left[\mathrm{Co}(\mathrm{CN})_{6}\right]$ [49]. There is a minor unidentified impurity that contributes most noticeably to the scattering at low angles, but we were able to show conclusively this was a separate phase as it was observed to decompose approximately at $450 \mathrm{~K}$. The structural model of [31] was then used as a starting model for Rietveld refinement of the primary $\left[\mathrm{C}_{3} \mathrm{~N}_{2} \mathrm{H}_{5}\right]_{2} \mathrm{Rb}\left[\mathrm{Co}(\mathrm{CN})_{6}\right]$ phase. We obtained an excellent fit-to-data; the corresponding structural and refinement parameters are summarized in table 1 . The as-refined structure itself is illustrated in figure $2 c$. The $\mathrm{Rb}^{+}$and $\mathrm{Co}^{3+}$ cations are ordered in a rocksalt arrangement; the $\mathrm{CN}^{-}$too are ordered, with $\mathrm{C}$-bound $\mathrm{Co}^{3+}$ and $\mathrm{Rb}^{+}$coordinated to nitrogen. This is as expected for cations with very different binding energies, in contrast to, for example, certain Prussian Blue analogues or the interpenetrated diamondoid cyanide frameworks based on $\mathrm{Zn}(\mathrm{CN})_{2}$ [51,52]. What is clear is that the imidazolium cations are indeed arranged in a coplanar fashion, which corresponds to the ferroquadrupolar state as described above. There is clear evidence of substantive thermal fluctuations in the cation orientations, as evidenced by the large atomic displacement parameters.

On further heating of $\left[\mathrm{C}_{3} \mathrm{~N}_{2} \mathrm{H}_{5}\right]_{2} \mathrm{Rb}\left[\mathrm{Co}(\mathrm{CN})_{6}\right]$, its X-ray diffraction pattern reflected a firstorder phase transition at approximately $480 \mathrm{~K}$. The most obvious change in the diffraction pattern was the coalescence of peaks, consistent with an ascent in symmetry. The high-temperature phase could be indexed in terms of the cubic space group $F m \overline{3} m$, which is consistent with the symmetry observed for other cubic double perovskites $[35,44,45]$ and is related to the $R \overline{3} m$ ambient-temperature cell as shown in figure $2 e$. A structural model in which the $\mathrm{C}_{3} \mathrm{~N}_{2} \mathrm{H}_{5}^{+}$ions are split across four sites-corresponding to the alignment of the rotational axis along each of the cubic $\langle 111\rangle$ body diagonals-was used as a starting point for Rietveld refinement. Again we obtained an excellent fit-to-data; the corresponding structural and refinement details are summarized in table 2. Our structural model suggests that in this high symmetry phase the $\mathrm{C}_{3} \mathrm{~N}_{2} \mathrm{H}_{5}^{+}$cations are no longer confined to rotate about a single body diagonal but are now able to switch between equivalent $\langle 111\rangle$ states. In this state, the orientational disorder of the $\mathrm{C}_{3} \mathrm{~N}_{2} \mathrm{H}_{5}^{+}$ cations is dynamic, but our diffraction measurements provide no information on the timescale of reorientation in these compounds. In principle, such information might be extractable using quasi-elastic neutron scattering measurements [24]. 


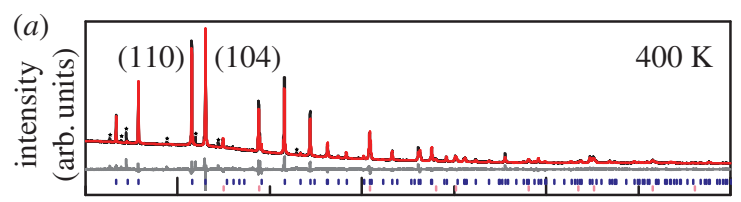

(c)

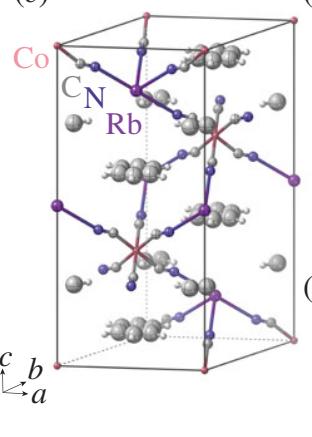

(d)

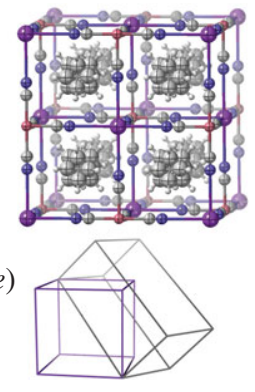

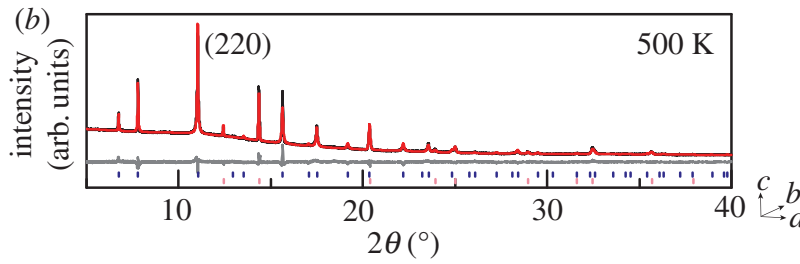

$2 \theta\left(^{\circ}\right)$

Figure 2. Rietveld refinements of synchrotron powder X-ray diffraction data for $\left[\mathrm{C}_{3} \mathrm{~N}_{2} \mathrm{H}_{5}\right]_{2} \mathrm{Rb}\left[\mathrm{Co}(\mathrm{CN})_{6}\right]$ in the $(a) R \overline{3} m$ phase at $400 \mathrm{~K}$ and $(b)$ the $F m \overline{3} m$ phase at $500 \mathrm{~K}$. X-ray diffraction data are shown in red, fit in blue and difference curve in grey. The estimated peak positions for $\left[\mathrm{C}_{3} \mathrm{~N}_{2} \mathrm{H}_{5}\right]_{2} \mathrm{Rb}\left[\mathrm{Co}(\mathrm{CN})_{6}\right]$ and $\mathrm{RbCl}$ are shown in navy and pink, respectively. Low-level impurities are highlighted with an asterisk $\left({ }^{*}\right)$. (c) The structure of $\left[\mathrm{C}_{3} \mathrm{~N}_{2} \mathrm{H}_{5}\right]_{2} \mathrm{Rb}\left[\mathrm{Co}(\mathrm{CN})_{6}\right]$ in the rhombohedral $R \overline{3} m$ phase at $400 \mathrm{~K}$ and $(d)$ cubic $\mathrm{Fm} \overline{3} \mathrm{~m}$ phase at $500 \mathrm{~K}$ with $\mathrm{Co}$ in pink, $\mathrm{Rb}$ in purple, $\mathrm{C}$ in grey, $\mathrm{N}$ in blue and $\mathrm{H}$ atoms shown in white. The atomic displacement parameters are shown with $50 \%$ probability. The relationship between these structures is shown in $(e)$.

Table 1. Crystallographic refinement details and structural model for $\left[\mathrm{C}_{3} \mathrm{~N}_{2} \mathrm{H}_{5}\right]_{2} \mathrm{Rb}\left[\mathrm{Co}(\mathrm{CN})_{6}\right]$ at $400 \mathrm{~K}$ as determined by powder synchrotron X-ray diffraction.

\begin{tabular}{|c|c|c|c|c|c|}
\hline space group & $R \overline{3} m$ & & & & \\
\hline$a / \AA$ & $8.79447(10)$ & & & & \\
\hline$c / \AA$ & $19.5493(3)$ & & & & \\
\hline$R_{\text {wp }}$ & $3.624 \%$ & & & & \\
\hline atom & $x$ & $y$ & $z$ & occ. & $B_{\text {iso }} / \AA^{2}$ \\
\hline Co1 & 0.667 & 0.333 & 0.333 & 1 & $1.58(11)$ \\
\hline $\mathrm{Rb} 1$ & 0 & 0 & 0.5 & 1 & $4.57(15)$ \\
\hline N1 & $0.8268(4)$ & $0.6536(7)$ & $0.4115(5)$ & 1 & $3.15(12)$ \\
\hline C1 & $0.7638(4)$ & $0.5275(7)$ & $0.3968(3)$ & 1 & $3.15(12)$ \\
\hline C2 & $0.1905(19)$ & $0.5953(10)$ & 0.418 & 0.50 & $9.36(18)$ \\
\hline N2 & 0.1905 & 0.5953 & 0.418 & 0.33 & $9.36(18)$ \\
\hline $\mathrm{H} 2 \mathrm{~A}$ & 0.0685 & 0.5343 & 0.416 & 0.83 & - \\
\hline C3 & $0.2630(9)$ & $0.7370(9)$ & 0.4192 & 0.50 & $9.36(18)$ \\
\hline N3 & 0.2630 & 0.7370 & 0.4192 & 0.33 & $9.36(18)$ \\
\hline $\mathrm{H} 3 \mathrm{~A}$ & 0.2009 & 0.7991 & 0.4211 & 0.83 & - \\
\hline
\end{tabular}

So we have observed that $\left[\mathrm{C}_{3} \mathrm{~N}_{2} \mathrm{H}_{5}\right]_{2} \mathrm{Rb}\left[\mathrm{Co}(\mathrm{CN})_{6}\right]$ does indeed exhibit a ferro-paraquadrupolar phase transition associated with a change in crystal symmetry from $R \overline{3} m$ to $F m \overline{3} m$. We proceeded to characterize the nature of this transition by following the evolution of the lattice parameters with temperature. Figure $3 a$ shows a 'film plot' of the evolution of the (110) and (104) rhombohedral reflections as they coalesce to become the (220) reflection of the cubic phase (these reflections are also highlighted in figure $2 a, b$ ). The corresponding normalized lattice parameter variation is shown in figure $3 b$, coloured according to the various fitting protocols outlined in $\S 3 c$ above. Evidence for the first-order nature of the phase transition is threefold. First, the coexistence of both rhombohedral and cubic phases across the phase transition is clearly evident in the raw diffraction data themselves. Second, there is hysteresis in the transition temperature: we find a 

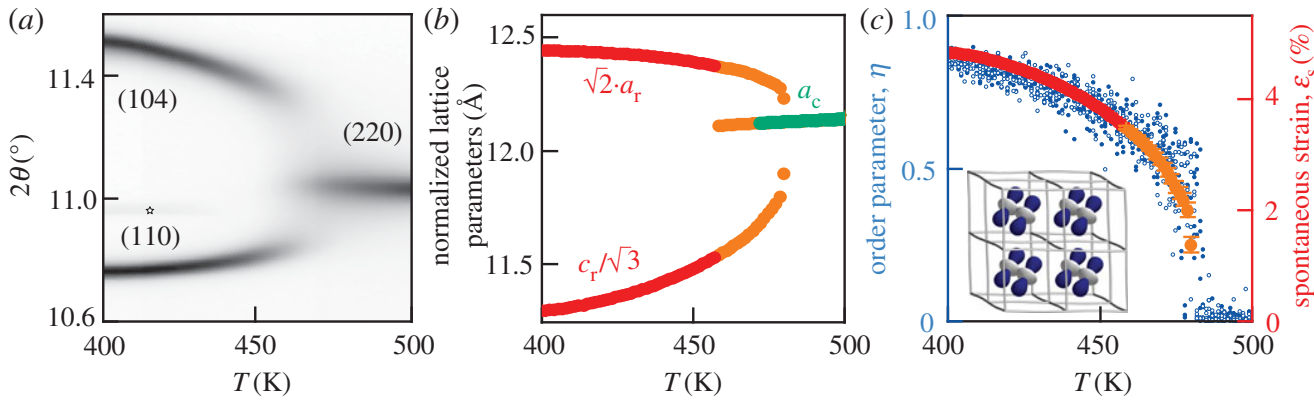

Figure 3. (a) A film plot of variable temperature diffraction data of $\left[\mathrm{C}_{3} \mathrm{~N}_{2} \mathrm{H}_{5}\right]_{2} \mathrm{Rb}\left[\mathrm{Co}(\mathrm{CN})_{6}\right]$ for a small section of $2 \theta$ in which the first-order phase transition is visible. (b) The lattice parameters extracted from batch variable temperature Pawley refinements. The colours represent three different refinement protocols: refinement of $R \overline{3} m$ phase only (red), $F m \overline{3} m$ phase only (green) and both refining (orange). (c) The thermal evolution of the spontaneous strain is shown (the colours correspond to data from the refinement protocols described above), superimposed on the order parameter obtained from Monte Carlo simulations shown in blue, filled circles $=$ cooling and open circles $=$ heating. The transition is well described by a simple model based on ferroquadrupolar interactions between neighbouring $\left[\mathrm{C}_{3} \mathrm{~N}_{2} \mathrm{H}_{5}\right]^{+}$molecules, which are disordered in the high-temperature phase, but align along a given $\langle 111\rangle$ axis as the temperature is lowered. This quadrupolar order is illustrated in the inset.

Table 2. Atomic positions for the $F m \overline{3} m$ phase of $\left[\mathrm{C}_{3} \mathrm{~N}_{2} \mathrm{H}_{5}\right]_{2} \mathrm{Rb}\left[\mathrm{Co}(\mathrm{CN})_{6}\right]$ at $500 \mathrm{~K}$.

\begin{tabular}{|c|c|c|c|c|c|}
\hline space group & $F m \overline{3} m$ & & & & \\
\hline$a / \AA$ & $12.1366(3)$ & & & & \\
\hline$R_{\text {wp }}$ & $3.078 \%$ & & & & \\
\hline atom & $x$ & $y$ & $z$ & occ. & $B_{\text {iso }} / \AA^{2}$ \\
\hline Co1 & 0.5 & 1 & 0 & 1 & $3.97(12)$ \\
\hline $\mathrm{Rb} 1$ & 0.5 & 0.5 & 0 & 1 & $9.87(18)$ \\
\hline N1 & 0.5 & $0.7654(6)$ & 0 & 1 & $4.5(2)$ \\
\hline C1 & 0.5 & $0.8342(7)$ & 0 & 1 & $4.9(3)$ \\
\hline$C 2$ & 0.31 & 0.7475 & 0.31 & 0.417 & $8.7(2)$ \\
\hline $\mathrm{H} 2$ & 0.3632 & 0.7475 & 0.3632 & 0.208 & \\
\hline
\end{tabular}

critical temperature of approximately $480 \mathrm{~K}$ on heating, and $440 \mathrm{~K}$ on cooling. ${ }^{2}$ And, third, the spontaneous strain-which we discuss in more detail below-shows a clear discontinuity at the transition temperature.

Although our focus is on the nature of ferroquadrupolar order in this system, the transition from cubic to rhombohedral cells is itself associated with a ferroelastic strain. Ferroelastic phase transitions are usually characterized by measuring the evolution of the spontaneous strain with temperature, an approach that has been applied widely to inorganic framework materials, coordination polymers, and metal-organic frameworks (MOFs) [53-56]. For the particular transition we observe here, the corresponding spontaneous strain is given by

$$
\varepsilon_{\mathrm{S}}=\frac{\sqrt{2} a-c / \sqrt{3}}{\sqrt{2} a+c / \sqrt{3}},
$$

where $a$ and $c$ are the rhombohedral cell parameters. Note that $\varepsilon_{\mathrm{S}}=0$ in the cubic phase. The temperature dependence of $\varepsilon_{\mathrm{S}}$ is shown in figure $3 c$, with the colour scheme corresponding to 
the various refinement protocols outlined above. From Landau theory, we expect the transition to be second order (continuous $\varepsilon_{\mathrm{S}}(T)$ ) if the symmetry breaking strain acts as the primary order parameter. This is not the case for the $480 \mathrm{~K}$ transition in $\left[\mathrm{C}_{3} \mathrm{~N}_{2} \mathrm{H}_{5}\right]_{2} \mathrm{Rb}\left[\mathrm{Co}(\mathrm{CN})_{6}\right]$. Hence this transition is an improper ferroelastic transition; in other words, the strain must be coupled to some other primary order parameter [53]. We postulate, then, that the multipolar symmetry of the A-site molecular cation is key to the symmetry breaking phase transition and so we sought to investigate whether the multipolar symmetry itself can act as the driving force for the phase transition, much like tilt instabilities in conventional perovskites.

Our approach was to investigate the evolution of ferroquadrupolar order on a simple cubic lattice using classical Monte Carlo (MC) simulations. As outlined in $\S 2$, the orientation of each imidazolium cation on the A-site sublattice of $\left[\mathrm{C}_{3} \mathrm{~N}_{2} \mathrm{H}_{5}\right]_{2} \mathrm{Rb}\left[\mathrm{Co}(\mathrm{CN})_{6}\right]$ can be represented by one of four quadrupolar states $\mathbf{Q}$ [equation (2.1)]. The MC energy used to drive our simulations was then given by the simplest quadrupolar interaction model

$$
E=-J \sum_{i, j} \mathbf{Q}_{i}: \mathbf{Q}_{j} .
$$

Here, $J>0$ is a measure of the strength of quadrupolar interactions, the sum is over nearest neighbours only, and the operation ':' corresponds to the inner (scalar) product

$$
\mathbf{Q}_{i}: \mathbf{Q}_{j}=\operatorname{Tr}\left[\mathbf{Q}_{i} \mathbf{Q}_{j}^{\mathrm{T}}\right] \text {. }
$$

This model exhibits a first-order phase transition at $T_{\mathrm{C}} \simeq 4.7 \mathrm{~J}$. An appropriate order parameter $\eta$ is given in terms of the relative population $x_{i}(i \in\{1, \ldots, 4\})$ of the four possible quadrupolar states:

$$
\eta=\frac{4}{3}\left[\sum_{i} x_{i}^{2}-\frac{1}{4}\right] .
$$

The temperature dependence of this order parameter, using a scaled temperature regime to match the experimental $T_{\mathrm{c}}$, is illustrated in figure $3 c$. The ferroquadrupolar ordering transition can be seen in the discontinuity of the order parameter on cooling as it tends from $\eta=0$ to $\eta=1$ as the $\mathrm{C}_{3} \mathrm{~N}_{2} \mathrm{H}_{5}{ }^{+}$cations begin to align. The experimental order parameter obtained from the spontaneous strain, as described above, is plotted superimposed on the MC results. The key result here is that our very simple toy model is able to reproduce remarkably well the main features of the phase transition. This suggests that the phase transition here is well described in terms of quadrupolar interactions between neighbouring $\mathrm{C}_{3} \mathrm{~N}_{2} \mathrm{H}_{5}{ }^{+}$cations. Based on our experimental value of $T_{\mathrm{c}}$, we determine an effective quadrupolar coupling constant, $J_{\text {eff }}$, of approximately $100 \mathrm{~K}$ for $\left[\mathrm{C}_{3} \mathrm{~N}_{2} \mathrm{H}_{5}\right]_{2} \mathrm{Rb}\left[\mathrm{Co}(\mathrm{CN})_{6}\right]$.

By way of context, a three-state Potts model-conceptually similar to the four-state Potts model we use here-was recently employed to describe the phase transition behaviour in the family of multiferroic dimethylammonium-formate MOFs. In that case, it was found that longer-range dipolar interactions were needed to fully explain the experimental data [57]. Our system appears to be simpler (perhaps fortuitously). We comment also that our results are consistent with the expectation that all three-dimensional Potts models with more than two Potts states give firstorder behaviour [58]. Had the high-temperature (paraquadrupolar) phase been better described in terms of continuously variable imidazolium orientations, then the Heisenberg model would have been a more physical representation of this system. However, the Heisenberg model exhibits a second-order phase transition [59], which is not what we observe experimentally. Hence, we suggest the nature of the phase transition we observe is indirect evidence in favour of a picture whereby imidazolium cations are still predominantly oriented perpendicular to a body diagonal of the perovskite cell even within the high-temperature paraquadrupolar state.

Having established the existence of a ferroquadrupolar transition in $\left[\mathrm{C}_{3} \mathrm{~N}_{2} \mathrm{H}_{5}\right]_{2} \mathrm{Rb}\left[\mathrm{Co}(\mathrm{CN})_{6}\right]$, we were interested to understand whether the temperature at which this transition occurs might be tuned by varying the framework chemistry. Consequently, we also measured variable-temperature powder synchrotron X-ray diffraction data for the related compound 


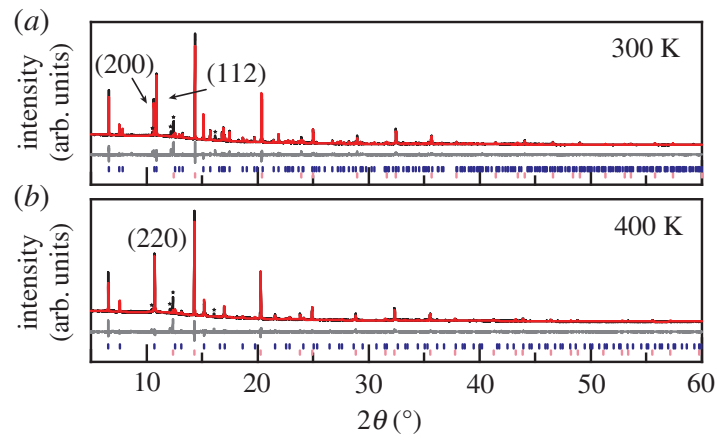

$(c)$

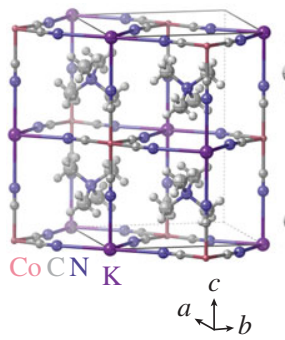

$(d)$

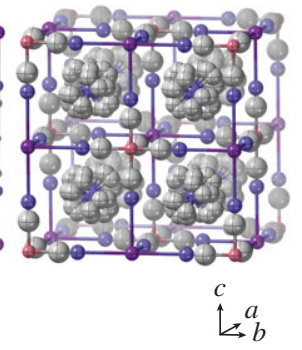

Figure 4. Rietveld refinements of synchrotron X-ray powder diffraction data of $\left[\mathrm{NMe}_{4}\right]_{2} \mathrm{~K}\left[\mathrm{Co}(\mathrm{CN})_{6}\right]$ at $(a) 300 \mathrm{~K}(14 / \mathrm{m})$ and $(b) 400 \mathrm{~K}(F \mathrm{~m} \overline{\mathrm{m}})$. Data are shown in red, fit in blue and difference curve in grey. The estimated peak positions for $\left[\mathrm{NMe}_{4}\right]_{2} \mathrm{~K}\left[\mathrm{Co}(\mathrm{CN})_{6}\right]$ and $\mathrm{KCl}$ are shown in navy and pink, respectively. Low-level impurities are highlighted with an asterisk $\left({ }^{*}\right)$. (c) The structure of $\left[\mathrm{NMe}_{4}\right]_{2} \mathrm{~K}\left[\mathrm{Co}(\mathrm{CN})_{6}\right]$ in the $/ 4 / m$ phase at $300 \mathrm{~K}$ and $(b)$ in the cubic $F m \overline{3} m$ phase at $400 \mathrm{~K}$, with $\mathrm{Co}$ in pink, $\mathrm{K}$ in purple, $\mathrm{C}$ in grey, $\mathrm{N}$ in blue and $\mathrm{H}$ atoms shown in white. The atom sizes reflect the atomic displacement parameters at $50 \%$ probability.

$\left[\mathrm{C}_{3} \mathrm{~N}_{2} \mathrm{H}_{5}\right]_{2} \mathrm{~K}\left[\mathrm{Co}(\mathrm{CN})_{6}\right]$; these data and their analysis are included as electronic supplementary material. We found evidence of a structural phase transition towards the cubic phase, which was incomplete up to our experimental limit of $500 \mathrm{~K}$. Hence, further heating will likely lead to a complete transition to the cubic $F m \overline{3} m$ phase, provided the transition occurs before decomposition. We have not explored this point further in our current study, but note that a higher $T_{\mathrm{c}}$ would correspond to a stronger ferroquadrupolar coupling constant $J$, which in turn is to be expected given the reduced unit cell constants relative to $\left[\mathrm{C}_{3} \mathrm{~N}_{2} \mathrm{H}_{5}\right]_{2} \mathrm{Rb}\left[\mathrm{Co}(\mathrm{CN})_{6}\right]$. Our attempts to synthesize $\left[\mathrm{C}_{3} \mathrm{~N}_{2} \mathrm{H}_{5}\right]_{2} \mathrm{Cs}\left[\mathrm{Co}(\mathrm{CN})_{6}\right]$ - which by this argument should have $T_{\mathrm{c}}<480 \mathrm{~K}$-were unsuccessful due to the empirical stability of the competing phase $\mathrm{Cs}_{3}\left[\mathrm{Co}(\mathrm{CN})_{6}\right]$.

\section{(b) Ferrooctupolar order in $\left(\mathrm{NMe}_{4}\right)_{2} \mathrm{BCO}(\mathrm{CN})_{6}, \mathrm{~B}=\mathrm{K}, \mathrm{Rb}, \mathrm{Cs}$}

We turn now to the related issue of ferrooctupolar order in the compositional family $\left[\mathrm{NMe}_{4}\right]_{2} \mathrm{~B}\left[\mathrm{Co}(\mathrm{CN})_{6}\right](\mathrm{B}=\mathrm{K}, \mathrm{Rb}, \mathrm{Cs})$. All but the K-containing member of this specific family have been characterized previously [60-62], and the corresponding hexacyanoferrates are known for all three B-site cations $[45,63]$. The system $\left(\mathrm{NMe}_{4}\right)_{2} \mathrm{~K}\left[\mathrm{Fe}(\mathrm{CN})_{6}\right]$ undergoes an order-disorder phase transition at approximately $350 \mathrm{~K}$ from a low-temperature $I 4 / \mathrm{m}$ phase-in which the $\mathrm{NMe}_{4}{ }^{+}$cations are collectively rotated around a common $\langle 100\rangle$ axis-to a high-temperature $F m \overline{3} m$ phase in which these rotations are disordered throughout the structure [45]. It is not known-or at least not clear-whether this same transition takes place in other members of the broader family. As outlined in $\S 2$, we can couch this rotational order-disorder transition in terms of ferrooctupolar order, and our main goals in this context were (i) to characterize the nature of this phase transition for the hexacyanocobaltate $\left[\mathrm{NMe}_{4}\right]_{2} \mathrm{~K}\left[\mathrm{Co}(\mathrm{CN})_{6}\right]$, (ii) to determine the extent to which this transition can be understood in terms of a simple microscopic model of multipolar interactions, and (iii) to investigate the possibility of tuning this phase transition using compositional variation.

Following the very same methodology used above for $\left[\mathrm{C}_{3} \mathrm{~N}_{2} \mathrm{H}_{5}\right]_{2} \mathrm{Rb}\left[\mathrm{Co}(\mathrm{CN})_{6}\right]$, we measured the X-ray powder diffraction pattern for $\left[\mathrm{NMe}_{4}\right]_{2} \mathrm{~K}\left[\mathrm{Co}(\mathrm{CN})_{6}\right]$ at various temperatures. For temperatures below $370 \mathrm{~K}$ our data were well described in terms of an $14 / \mathrm{m}$ structural model based on that reported for $\left(\mathrm{NMe}_{4}\right)_{2} \mathrm{~K}\left[\mathrm{Fe}(\mathrm{CN})_{6}\right]$ [45]; at higher temperatures our data were consistent with the aristotypic $F m \overline{3} m$ structure as reported for the hexacyanoferrate in [45]. Full details of our refinements are given as electronic supplementary material, but we show representative fits and structural models for data collected at 300 and $400 \mathrm{~K}$ in figure 4. 

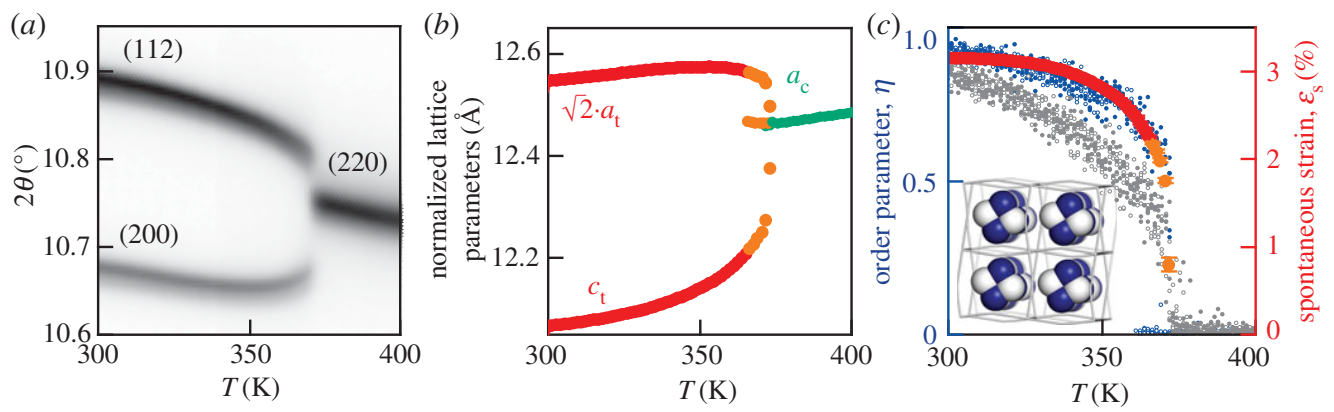

Figure 5. (a) A film plot of variable temperature diffraction data of $\left[\mathrm{NMe}_{4}\right]_{2} \mathrm{~K}\left[\mathrm{Co}(\mathrm{CN})_{6}\right]$ for a small section of $2 \theta$ in which the first-order phase transition is visible. (b) The lattice parameters extracted from batch variable temperature Pawley refinements. The colours represent three different refinement protocols: refinement of $/ 4 / m$ phase only (red), $F m \overline{3} m$ phase only (green) and both refining (orange). (c) The thermal evolution of the spontaneous strain is shown (the colours correspond to data from the refinement protocols described above), superimposed on the order parameter obtained from Monte Carlo simulations. The results of the six-state Potts model are shown in blue and those of the dot-product model in grey. The symmetry lowering is characterized by cooperative rotations of neighbouring $\mathrm{NMe}_{4}{ }^{+}$cations about a given $\langle 100\rangle$ axis of the pseudocubic cage. As the temperature is lowered the cations rotate cooperatively around a single $\langle 100\rangle$ axis. The octupolar order is shown in the inset, looking down the axis of rotation.

The character of the phase transition is evident from our powder synchrotron X-ray diffraction patterns collected between 300 and $400 \mathrm{~K}$ : we find the transition to be first order and to occur at $T_{\mathrm{C}} \sim 370 \mathrm{~K}$. The nature of the transition is clearly evident in the behaviour of the (200) and (112) reflections (I4/m indexing) around $2 \theta \sim 11^{\circ}$-as shown in figure $4 a$-and the evolution of these two reflections with temperature is shown as a film plot in figure $5 a$. The temperature dependence of the normalized lattice parameters is shown in figure $5 b$. Again, this transition is also ferroelastic, and we show the temperature evolution of the spontaneous strain

$$
\varepsilon_{\mathrm{S}}=\frac{\sqrt{6}(\sqrt{2} a-c)}{2 \sqrt{2} a+c} .
$$

in figure $5 c$. The temperature dependence of the spontaneous strain shows a discontunity at $T_{\mathcal{C}}$, reflected in both the lattice parameter data as well as the film plot and is indicative of an improper ferroelastic transition. Moreover, the first-order nature of the phase transition is consistent with the subtle thermal hysteresis from modulated differential scanning calorimetry (MDSC) for the Fe analogue [45].

The most significant structural change between the low and high symmetry phases involves the absence or presence of multiple rotation states for the $\mathrm{NMe}_{4}{ }^{+}$cations. While the orientation of the cation is fixed in $I 4 / m$, the increase in temperature allows the cation to switch between symmetry-equivalent rotation states. On cooling, the orientations of the $\mathrm{NMe}_{4}{ }^{+}$cations are characterized by cooperative rotation by some finite angle about a given $\langle 100\rangle$ axis. This rotation axis corresponds to the tetragonal $c$-axis when the cation orientations are frozen in an order. Coupled to this collective rotation is tilting of the $\mathrm{CoC}_{6}$ and $\mathrm{KN}_{6}$ octahedra, for which the corresponding tilt is given by $a^{0} a^{0} c^{-}$in the Glazer notation [64]. The tilt angle is widely used as the order parameter in describing phase transitions in double (and indeed single) perovskites. Since it is impossible here to determine whether it is the interaction and concerted rotations of $\mathrm{NMe}_{4}{ }^{+}$ cations or tilting of the metal-cyanide octahedra that is acting as the primary order parameter, we note simply that there is strong coupling between the tilting and rotational degrees of freedom for this material.

Again we turned to MC simulations to attempt to model the phase transition behaviour we observed experimentally. The individual rotation (三 octupolar) states were represented by axial vectors $\mathbf{e} \in\langle 100\rangle$, and we now considered two different interaction models. The first involved 
(a)

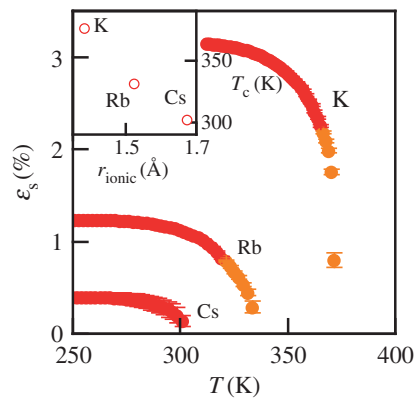

(b)

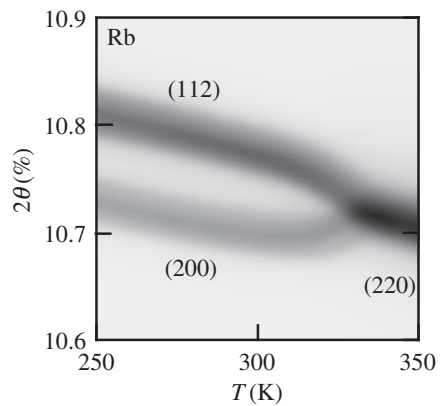

(c)

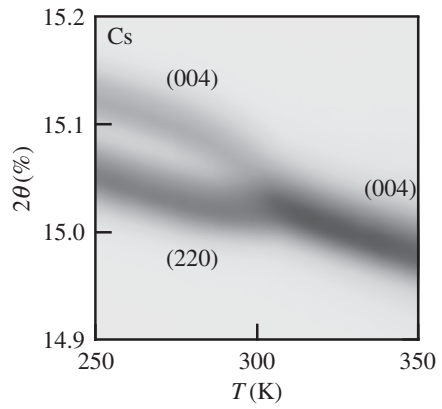

Figure 6. (a) Thermal evolution of the spontaneous strain for the family $\left[\mathrm{NMe}_{4}\right]_{2} \mathrm{~B}\left[\mathrm{Co}(\mathrm{CN})_{6}\right], \mathrm{B}=\mathrm{K}, \mathrm{Rb}$, $\mathrm{Cs}$ and in the inset: $T_{c}$ versus ionic radius: as the ionic radius of $B$ is increased the coupling between neighbouring octupole rotations is weakened. Film plots of thermal evolution of chosen reflections for $(b) B=R b$ and $(c) B=C$ s in which the phase transition is clearly visible.

taking the inner product of the nearest neighbour rotation vectors such that

$$
E=-J \sum_{i, j} \mathbf{e}_{i} \cdot \mathbf{e}_{j} .
$$

We will refer to this as the 'dot-product model'. The second model was a six-state Potts model (similar to that employed above for our imidazolium system), for which

$$
E=-J \delta\left(\mathbf{e}_{i}-\mathbf{e}_{j}\right) .
$$

Here, the delta function $\delta(\mathbf{u})$ is equal to one if and only if its argument $\mathbf{u}$ is the zero vector and is zero otherwise. Physically, the two interactions models can be interpreted as follows: in both systems rotation of neighbouring cations about the same axis serves to reduce the energy of the system. In the Potts model, a neighbouring cation rotating about any other axis has a neutral effect on the energy, whereas in the dot-product model a neighbouring cation rotating in the opposite sense-i.e. $\mathbf{e}_{i}=[100]$ and $\mathbf{e}_{j}=[100]$-will raise the energy of the system.

Both models show a phase transition, but it is only for the Potts model that this transition is first order. We can see this difference by calculating the temperature dependence of the order parameter

$$
\eta=\frac{6}{5}\left[\sum_{i} x_{i}^{2}-\frac{1}{6}\right],
$$

where the $x_{i}$ are the relative populations of the six possible rotation states. The results for both simulations, with the data scaled such that $T_{\mathrm{C}}$ matches that found experimentally, are shown in figure $5 c$. Here, our data are superimposed on the spontaneous strain for direct comparison. What seems clear is that the Potts model gives the truer representation of our experimental data. While we cannot rule out the relevance of more complex models, our results suggest that nearestneighbour ferrooctupolar interactions are sufficient to drive the phase transition we observe in $\left[\mathrm{NMe}_{4}\right]_{2} \mathrm{~K}\left[\mathrm{Co}(\mathrm{CN})_{6}\right]$. The effective interaction strength is about $70 \mathrm{~K}$ for this system.

We now turn to the final point of tuning the nature or temperature of this ferrooctupolar phase transition via chemical substitution. In this case, we were able to prepare samples of both $\left[\mathrm{NMe}_{4}\right]_{2} \mathrm{Rb}\left[\mathrm{Co}(\mathrm{CN})_{6}\right]$ and $\left[\mathrm{NMe}_{4}\right]_{2} \mathrm{Cs}\left[\mathrm{Co}(\mathrm{CN})_{6}\right]$; our X-ray diffraction measurements indicated the corresponding crystal structures had $I 4 / m$ and $I 2 / m$ symmetry, respectively, as reported previously [60-62]. The corresponding unit cells reflected the increased ionic radii of $\mathrm{Rb}^{+}$and $\mathrm{Cs}^{+}$ relative to $\mathrm{K}^{+}$. Variable temperature $\mathrm{X}$-ray powder diffraction measurements (200-400 K) showed a phase transition to the cubic $F m \overline{3} m$ structure at $T_{\mathrm{C}} \sim 330$ and $302 \mathrm{~K}$ for $\left[\mathrm{NMe}_{4}\right]_{2} \mathrm{Rb}\left[\mathrm{Co}(\mathrm{CN})_{6}\right]$ and $\left[\mathrm{NMe}_{4}\right]_{2} \mathrm{Cs}\left[\mathrm{Co}(\mathrm{CN})_{6}\right]$, respectively. Our experimental data are shown more fully in electronic supplementary material, but we capture in figure $6 b, c$ the experimental signature of ascent in 
symmetry. We extracted from these data the temperature dependence of the unit cell parameters; full details are given as electronic supplementary material. From these parameters, we could

determine the spontaneous strains and their temperature dependence. For the Rb-containing compound, we used equation (4.5), and for the Cs analogue we have

$$
\varepsilon_{\mathrm{S}}=\sqrt{\frac{\left(\sqrt{2} a-a_{0}\right)^{2}+\left(\sqrt{2} b-a_{0}\right)^{2}+\left(c-a_{0}\right)^{2}}{a_{0}^{2}}},
$$

where $a_{0}=(1 / 3)(\sqrt{2} a+\sqrt{2} b+c)$ (i.e. the estimated cubic lattice parameter based on the arithmetic mean of all possible strain tensors of an 'average' zero-strain structure). Our results are collated in figure $6 a$.

We find three key differences in the phase transition behaviour as the size of the alkali metal is increased. First, the transition shifts to a lower temperature; second, the magnitude of the spontaneous strain is reduced; and, third, the nature of the phase transition is itself changed, such that it appears increasingly like a continuous second order transition. Our interpretation is that by increasing the alkali metal cation radius and thereby the size of the pseudocubic cage, we weaken the coupling between neighbouring $\mathrm{NMe}_{4}{ }^{+}$cations and progress from Potts to Heisenberg regimes.

\section{Conclusion}

From an experimental viewpoint, our key result has been to characterize a series of multipolar ferroic order-disorder transitions in various cyanoelpasolites. We have demonstrated that the paramultipolar high-symmetry state is thermally accessible, and hence switching between different ferroic states under an appropriate multipolar external field is possible in principle. Because the two transitions we study are also ferroelastic, external strain can function as a direct or indirect source of such a field. For example, uniaxial compression of single-crystal $\left[\mathrm{NMe}_{4}\right]_{2} \mathrm{~B}\left[\mathrm{Co}(\mathrm{CN})_{6}\right]$ samples might be expected to drive $F m \overline{3} m \rightarrow I 4 / m$ ferrooctupolar order. We have shown also how compositional variation provides a straightforward strategy for turning the phase transition temperature in these various systems.

But from a conceptual viewpoint what we have achieved is to demonstrate that multipolar order in these molecular perovskites can mimic the behaviour of remarkably simple statistical mechanical models. Although the underlying physics at play will be relatively complex-likely driven by an interplay between directional hydrogen bonding and local strains-these particular systems seem to be well described in terms of vastly simpler Potts-type models. If this point proves to be relatively general, then there is scope for quite powerful control over symmetry lowering phenomena in molecular perovskites. For example, the symmetry relationship between A-site cation geometry and the $T_{d}$ point symmetry of the aristotypic crystallographic site effectively determines the type of multipolar degree of freedom at play, and the corresponding ferroic order determines the parent-child space group relationship. The rules developed in [39] then outline how such order might be combined with other phenomena-such as collective Jahn-Teller order - to drive e.g. the emergence of bulk polarization.

So it seems that the development of certain rules for controlling multipolar order in molecular perovskites may be within reach, with molecular symmetry determining the relevant multipolar type and chemistry controlling the effective strength of interaction. Perhaps the most important remaining question is what drives the particular sign of the interaction constant? It was recently shown, for example, that it is possible to switch between ferroquadrupolar and antiferroquadrupolar order in formate perovskites by varying composition [37]. But the driving force for this change is not at all well understood. Can one imagine a structural analogue of the Goodenough-Kanamori rules for quadrupolar order in molecular perovskites? Whether possible or not, we would suggest that phenomenological studies of multipolar order-disorder transitions—such as the present work-will likely play an important role in laying the empirical 
foundation for intentionally exploiting symmetry-breaking processes in functional perovskite analogues.

Data accessibility. This article has no additional data.

Authors' contributions. C.S.C., H.J.G., J.M.B., H.L.B.B. and A.S. carried out the synthesis and diffraction measurements. C.S.C., H.J.G. and A.S. performed Monte Carlo simulations. All authors performed the data analysis. C.S.C. and A.L.G. wrote the manuscript with input from all authors.

Competing interests. The authors declare that they have no competing interests.

Funding. The authors gratefully acknowledge funding from the Leverhulme Trust (Grant RPG-2015-292), the E.R.C. (grant no. 788144) and the Swiss National Science Foundation (fellowship to A.S.).

Acknowledgements. This study has made use of a BAG allocation on the I11 beamline at the Diamond Light Source, for which we are extremely grateful. The authors gratefully acknowledge funding from the Leverhulme Trust (Grant RPG-2015-292), the E.R.C. (grant no. 788144), the Swiss National Science Foundation (fellowship to A.S.) and Uppsala University (fellowship to H.L.B.B.).

\section{References}

1. von Hippel A, Breckenridge RG, Chesley FG, Tisza L. 1946 High dielectric constant ceramics. Ind. Eng. Chem. 38, 1097-1109. (doi:10.1021/ie50443a009)

2. Matthias BT. 1951 Ferroelectricity. Science 113, 591-596. (doi:10.1126/science.113.2943.591)

3. Aizu K. 1969 Possible species of 'ferroelastic' crystals and of simultaneously ferroelectric and ferroelastic crystals. J. Phys. Soc. Jpn. 27, 387-396. (doi:10.1143/JPSJ.27.387)

4. Wadhawan VK. 2000 Introduction to ferroic materials. New York, USA: Gordon and Breach.

5. Spaldin NA, Fiebig M. 2005 The renaissance of magnetoelectric multiferroics. Science 309, 391-392. (doi:10.1126/science.1113357)

6. Aizu K. 1969 Fundamentals of mutual conversion of electrical energy and mechanical energy by simultaneously ferroelectric and ferroelastic crystals. Jap. J. Appl. Phys. 8, 1424-1434. (doi:10.1143/JJAP.8.1424)

7. Glazer AM. 2011 A brief history of tilts. Phase Transitions 84, 405-420. (doi:10.1080/ 01411594.2010.544732)

8. Angel RJ, Zhao J, Ross NL. 2005 General rules for predicting phase transitions in perovskites due to octahedral tilting. Phys. Rev. Lett. 95, 025503. (doi:10.1103/PhysRevLett.95.025503)

9. Burdett JK. 1981 Use of the Jahn-Teller theorem in inorganic chemistry. Inorg. Chem. 20, 19591962. (doi:10.1021/ic50221a003)

10. Goodenough JB. 1955 Theory of the role of covalence in the perovskite-type manganites [La, M(II)] $\mathrm{MnO}_{3}$. Phys. Rev. 100, 564-573. (doi:10.1103/PhysRev.100.564)

11. Goodenough JB. 1958 An interpretation of the magnetic properties of the perovskitetype mixed crystals $\mathrm{La}_{1-x} \mathrm{Sr}_{x} \mathrm{CoO}_{3-\lambda}$. J. Phys. Chem. Solids 6, 287-297. (doi:10.1016/00223697(58)90107-0)

12. Kanamori J. 1959 Superexchange interaction and symmetry properties of electron orbitals. J. Phys. Chem. Solids 10, 87-98. (doi:10.1016/0022-3697(59)90061-7)

13. Tong ML, Ru J, Wu YM, Chen XM, Chang HC, Mochizuki K, Kitagawa S. 2003 Cation-templated construction of three-dimensional $\alpha$-Po cubic-type $\left[\mathrm{M}(\mathrm{dca})_{3}\right]^{-}$networks. Syntheses, structures and magnetic properties of $\mathrm{A}\left[\mathrm{M}(\mathrm{dca})_{3}\right]$ (dca = dicyanamide; for $\mathrm{A}=$ benzyltributylammonium, $\mathrm{M}=\mathrm{Mn}^{2+}, \mathrm{Co}^{2+}$; for $\mathrm{A}=$ benzyltriethylammonium, $\mathrm{M}=\mathrm{Mn}^{2+}$, $\mathrm{Fe}^{2+}$ ). New J. Chem. 27, 779-782. (doi:10.1039/b300760j)

14. Zhao XH, Huang XC, Zhang SL, Shao D, Wei HY, Wang XY. 2013 Cation-dependent magnetic ordering and room-temperature bistability in azido-bridged perovskite-type compounds. J. Am. Chem. Soc. 135, 16006-16009. (doi:10.1021/ja407654n)

15. Saparov B, Mitzi DB. 2016 Organic-inorganic perovskites: Structural versatility for functional materials design. Chem. Rev. 116, 4558-4596. (doi:10.1021/acs.chemrev.5b00715)

16. Li W, Wang Z, Deschler F, Gao S, Friend RH, Cheetham AK. 2017 Chemically diverse and multifunctional hybrid organic-inorganic perovskites. Nat. Rev. Mater. 2, 16099. (doi:10.1038/natrevmats.2016.99)

17. Stroppa A, Di Sante D, Barone P, Bokdam M, Kresse G, Franchini C, Whangbo MH, Picozzi S. 2014 Tunable ferroelectric polarization and its interplay with spin-orbit coupling in tin iodide perovskites. Nat. Commun. 5, 5900. (doi:10.1038/ncomms6900) 
18. Chen S, Shang R, Hu KL, Wang ZM, Gao S. $2014\left[\mathrm{NH}_{2} \mathrm{NH}_{3}\right]\left[\mathrm{M}(\mathrm{HCOO})_{3}\right]\left(\mathrm{M}=\mathrm{Mn}^{2+}\right.$, $\mathrm{Zn}^{2+}, \mathrm{Co}^{2+}$ and $\mathrm{Mg}^{2+}$ ): structural phase transitions, prominent dielectric anomalies and negative thermal expansion, and magnetic ordering. Inorg. Chem. Front. 1, 83-98. (doi:10.1039/C3QI00034F)

19. Jain P, Ramachandran V, Clark RJ, Zhou HD, Toby BH, Dalal NS, Kroto HW, Cheetham AK. 2009 Multiferroic behavior associated with an order-disorder hydrogen bonding transition in metal-organic frameworks (MOFs) with the perovskite $\mathrm{ABX}_{3}$ architecture. J. Am. Chem. Soc. 131, 13625-13 627. (doi:10.1021/ja904156s)

20. Pato-Doldán B, Gómez-Aguirre LC, Bermúdez-García JM, Sánchez-Andújar M, Fondado A, Mira J, Castro-García S, Señarís-Rodríguez MA. 2013 Coexistence of magnetic and electrical order in the new perovskite-like $\left(\mathrm{C}_{3} \mathrm{~N}_{2} \mathrm{H}_{5}\right)\left[\mathrm{Mn}(\mathrm{HCOO})_{3}\right]$ formate. RSC Adv. 3, 22 404-22 411. (doi:10.1039/c3ra43165g)

21. Jain P et al. 2016 Switchable electric polarization and ferroelectric domains in a metal-organic framework. npj Quantum Mater. 1, 16012. (doi:10.1038/npjquantmats.2016.12)

22. Besara T, Jain P, Dalal NS, Kuhns PL, Reyes AP, Kroto HW, Cheetham AK. 2011 Mechanism of the order-disorder phase transition, and glassy behavior in the metalorganic framework $\left[\left(\mathrm{CH}_{3}\right)_{2} \mathrm{NH}_{2}\right] \mathrm{Zn}(\mathrm{HCOO})_{3}$. Proc. Natl Acad. Sci. USA 108, 6828-6832. (doi:10.1073/pnas.1102079108)

23. Lee MM, Teuscher J, Miyasaka T, Murakami TN, Snaith HJ. 2012 Efficient hybrid solar cells based on meso-superstructured organometal halide perovskites. Science 338, 643-647. (doi:10.1126/science.1228604)

24. Leguy AMA et al. 2015 The dynamics of methylammonium ions in hybrid organic-inorganic perovskite solar cells. Nat. Commun. 6, 7124. (doi:10.1038/ncomms8124)

25. Whitfield PS, Herron N, Guise WE, Page K, Cheng YQ, Milas I, Crawford MK. 2016 Structures, phase transitions and tricritical behavior of the hybrid perovskite methyl ammonium lead iodide. Sci. Rep. 6, 35685. (doi:10.1038/srep35685)

26. Gómez-Aguirre LC et al. 2016 Coexistence of three ferroic orders in the multiferroic compound $\left[\left(\mathrm{CH}_{3}\right)_{4} \mathrm{~N}\right]\left[\mathrm{Mn}\left(\mathrm{N}_{3}\right)_{3}\right]$ with perovskite-like structure. Chem. Eur. J. 22, 7863-7870. (doi:10.1002/chem.201503445)

27. Kieslich G, Goodwin AL. 2017 The same and not the same: molecular perovskites and their solid-state analogues. Mater. Horiz. 4, 362-366. (doi:10.1039/C7MH00107J)

28. Xu WJ, Du ZY, Zhang WX, Chen XM. 2016 Structural phase transitions in perovskite compounds based on diatomic or multiatomic bridges. CrystEngComm 18, 7915. (doi:10.1039/C6CE01485B)

29. Xie KP, Xu WJ, He CT, Huang B, Du ZY, Su YJ, Zhang WX, Chen XM. 2016 Orderdisorder phase transition in the first thiocyanate-bridged double perovskite-type coordination polymer: $\left[\mathrm{NH}_{4}\right]_{2}\left[\mathrm{NiCd}(\mathrm{SCN})_{6}\right]$. CrystEngComm 18, 4495-4498. (doi:10.1039/C6CE00898D)

30. Dove MT. 1997 Theory of displacive phase transitions in minerals. Am. Mineral. 82, 213-244. (doi:10.2138/am-1997-3-401)

31. Zhang W, Cai Y, Xiong R, Yoshikawa H, Awaga K. 2010 Exceptional dielectric phase transitions in a perovskite-type cage compound. Angew. Chem. Int. Ed. 49, 6608-6610. (doi:10.1002/anie.201001208)

32. Shi C, Yu CH, Zhang W. 2016 Predicting and screening dielectric transitions in a series of hybrid organic-inorganic double perovskites via an extended tolerance factor approach. Angew. Chem. Int. Ed. 55, 5798-5802. (doi:10.1002/anie.201602028)

33. Du ZY, Xu TT, Huang B, Su YJ, Xue W, He CT, Zhang WX, Chen XM. 2015 Switchable guest molecular dynamics in a perovskite-like coordination polymer toward sensitive thermoresponsive dielectric materials. Angew. Chem. Int. Ed. 54, 914-918. (doi:10.1002/anie.201408491)

34. Hu KL, Kurmoo M, Wang Z, Gao S. 2009 Metal-organic perovskites: Synthesis, structures, and magnetic properties of $\left[\mathrm{C}\left(\mathrm{NH}_{2}\right)_{3}\right]\left[\mathrm{M}^{\mathrm{II}}(\mathrm{HCOO})_{3}\right]\left(\mathrm{M}=\mathrm{Mn}, \mathrm{Fe}, \mathrm{Co}, \mathrm{Ni}, \mathrm{Cu}\right.$, and $\mathrm{Zn} ; \mathrm{C}\left(\mathrm{NH}_{2}\right)_{3}=$ guanidinium). Chem. Eur. J. 15, 12 050-12 064. (doi:10.1002/chem.v15:44)

35. Xu WJ, Xie KP, Xiao ZF, Zhang WX, Chen XM. 2016 Controlling two-step phase transitions and dielectric responses by A-site cations in two perovskite-like coordination polymers. Cryst. Growth Des. 16, 7212-7217. (doi:10.1021/acs.cgd.6b01404)

36. Stroppa A, Jain P, Barone P, Marsman M, Perez-Mato JM, Cheetham AK, Kroto HW, Picozzi S. 2011 Electric control of magnetization and interplay between orbital ordering 
and ferroelectricity in a multiferroic metal-organic framework. Angew. Chem. 123, 5969-5972. (doi:10.1002/ange.v123.26)

37. Evans NL, Thygesen PMM, Boström HLB, Reynolds EM, Collings IE, Phillips AE, Goodwin AL. 2016 Control of multipolar and orbital order in perovskite-like $\left[\mathrm{C}\left(\mathrm{NH}_{2}\right)_{3}\right] \mathrm{Cu}_{x} \mathrm{Cd}_{1-x}(\mathrm{HCOO})_{3}$ metal-organic frameworks. J. Am. Chem. Soc. 138, 9393-9396. (doi:10.1021/jacs.6b05208)

38. Donlan EA, Boström HLB, Geddes HS, Reynolds EM, Goodwin AL. 2017 Compositional nanodomain formation in hybrid formate perovskites. Chem. Commun. 53, 11233-11236. (doi:10.1039/C7CC06928F)

39. Boström HLB, Senn MS, Goodwin AL. 2018 Recipes for improper ferroelectricity in molecular perovskites. Nat. Commun. 9, 2380. (doi:10.1038/s41467-018-04764-x)

40. Mydosh JA, Oppeneer PM. 2011 Hidden order, superconductivity, and magnetism: the unsolved case of URu $\mathrm{Si}_{2}$. Rev. Mod. Phys. 83, 1301-1322. (doi:10.1103/RevModPhys.83.1301)

41. Paddison JAM, Jacobsen H, Petrenko OA, Fernández-Díaz MT, Deen PP, Goodwin AL. 2015 Hidden order in spin-liquid $\mathrm{Gd}_{3} \mathrm{Ga}_{5} \mathrm{O}_{12}$. Science 350, 179-181. (doi:10.1126/science.aaa5326)

42. Šimènas M, Balčiūnas S, Mączka M, Banys J, Tornau EE. 2017 Exploring the antipolar nature of methylammonium lead halides: a Monte Carlo and pyrocurrent study. J. Phys. Chem. Lett. 8, 4906-4911. (doi:10.1021/acs.jpclett.7b02239)

43. Tan LZ, Zheng F, Rappe AM. 2017 Intermolecular interactions in hybrid perovskites understood from a combined density functional theory and effective Hamiltonian approach. ACS Energy Lett. 2, 937-942. (doi:10.1021/acsenergylett.7b00159)

44. Qian K, Shao F, Yan Z, Pang J, Chen X, Yang C. 2016 A perovskite-type cage compound as a temperature-triggered dielectric switchable material. CrystEngComm 18, 7671-7674. (doi:10.1039/C6CE01421F)

45. Xu WJ, Chen SL, Hu ZT, Lin RB, Su YJ, Zhang WX, Chen XM. 2016 The cation-dependent structural phase transitions and dielectric response in a family of cyano-bridged perovskitelike coordination polymers. Dalton Trans. 45, 4224. (doi:10.1039/C5DT03481G)

46. Goodwin AL, Keen DA, Tucker MG, Dove MT, Peters L, Evans JSO. 2008 Argentophilicitydependent colossal thermal expansion in extended Prussian blue analogues. J. Am. Chem. Soc. 130, 9660-9661. (doi:10.1021/ja803623u)

47. Coelho AA. 2007 TOPAS-Academic, version 4.1 (Computer Software). Coelho Software, Brisbane.

48. Potts RB. 1952 Some generalized order-disorder transformations. Proc. Camb. Phil. Soc. 48, 106-109. (doi:10.1017/S0305004100027419)

49. Zhang X, Shao XD, Li SC, Cai Y, Yao YF, Xiong RG, Zhang W. 2015 Dynamics of a caged imidazolium cation-toward understanding the order-disorder phase transition and the switchable dielectric constant. Chem. Commun. 51, 4568-4571. (doi:10.1039/C4CC08693G)

50. Duncan HD, Beake EOR, Playford HY, Dove MT, Phillips AE. 2017 Local structure of a switchable dielectric Prussian blue analogue. CrystEngComm 19, 7317-7321. (doi:10.1039/ C7CE01883E)

51. Sharpe AG. 1976 The chemistry of Cyano complexes of the transition metals. London: Academic Press Inc. (London) Ltd.

52. Hoskins BF, Robson R. 1990 Design and construction of a new class of scaffoldinglike materials comprising infinite polymeric frameworks of 3D-linked molecular rods. A reappraisal of the zinc cyanide and cadmium cyanide structures and the synthesis

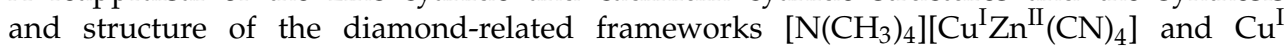
$\left[4,4^{\prime}, 4^{\prime \prime}, 4^{\prime \prime \prime}\right.$-tetracyanotetraphenylmethane $] \mathrm{BF}_{4} \cdot x \mathrm{C}_{6} \mathrm{H}_{5} \mathrm{NO}_{2}$. J. Am. Chem. Soc. 112, 1546-1554. (doi:10.1021/ja00160a038)

53. Salje EKH. 1990 Phase transitions in ferroelastic and coelastic crystals: an introduction for mineralogists, material scientists and physicists. Cambridge, UK: Cambridge University Press.

54. Salje EK. 2012 Ferroelastic materials. Annu. Rev. Mater. Res. 42, 265-283. (doi:10.1146/ annurev-matsci-070511-155022)

55. Li W et al. 2013 Ferroelasticity in a metal-organic framework perovskite; towards a new class of multiferroics. Acta. Mater. 61, 4928-4938. (doi:10.1016/j.actamat.2013.04.054)

56. Du ZY, Zhao YP, Zhang WX, Zhou HL, He CT, Xue W, Wang BY, Chen XM. 2014 Above-roomtemperature ferroelastic phase transition in a perovskite-like compound $\left[\mathrm{N}\left(\mathrm{CH}_{3}\right)_{4}\right]\left[\mathrm{Cd}\left(\mathrm{N}_{3}\right)_{3}\right]$. Chem. Commun. 50, 1989-1991. (doi:10.1039/c3cc48581a) 
57. Šimėnas M, Balčiūnas S, Mạczka M, Banys J, Tornau EE. 2016 Structural phase transition in perovskite metal-formate frameworks: a Potts-type model with dipolar interactions. Phys. Chem. Chem. Phys. 18, 18528. (doi:10.1039/C6CP03414D)

58. Wu FY. 1982 The Potts model. Rev. Mod. Phys. 54, 235-268. (doi:10.1103/RevModPhys.54.235)

59. Stephenson RL, Wood PJ. 1970 On the spontaneous magnetization of the classical Heisenberg ferromagnet. J. Phys. C: Solid State Phys. 3, 90-93. (doi:10.1088/0022-3719/3/1/012)

60. Ziegler B, Witzel M, Babel D. 1991 Tetragonale Cyanoelpasolithe: Die Kristallstrukturen von $\left[\mathrm{N}\left(\mathrm{CH}_{3}\right)_{4}\right]_{2} \mathrm{KMn}(\mathrm{CN})_{6}$ und $\left[\mathrm{N}\left(\mathrm{CH}_{3}\right)_{4}\right]_{2} \mathrm{RbCo}(\mathrm{CN})_{6}$. Z. Anorg. Allg. Chem. 600, 239-248. (doi:10.1002/(ISSN)1521-3749)

61. Griebler WD, Babel D. 1980 Über Cyanoelpasolithe $\mathrm{A}_{2} \mathrm{~B}_{2} \mathrm{M}(\mathrm{CN})_{6}$ mit $\mathrm{A}=$ Tetramethylammonium und das fluoride $\left[\mathrm{N}_{(}\left(\mathrm{CH}_{3}\right)_{4}\right]_{2} \mathrm{CsFeF}_{6}$. Liebigs Ann. Chem. 1980, 1549-1556. (doi:10.1002/(ISSN)1099-0690)

62. Peschel S, Babel D. 1994 Zur Kristallstruktur der Cyanoelpasolithe $\left[\mathrm{N}\left(\mathrm{CH}_{3}\right)_{4}\right]_{2} \mathrm{CsCo}(\mathrm{CN})_{6}$ and $\left[\mathrm{H}_{3} \mathrm{NCH}_{3}\right]_{2} \mathrm{NaFe}(\mathrm{CN})_{6}$. Z. Naturforsch. 49b, 1373-1380. (doi:10.1515/znb-1994-1011)

63. Schwarten M, Ziegler B, Witzel M, Babel D. 1996 Rontgenstrukturuntersuchungen an Elpasolith-verwandten Hexacyanokomplexen. Z. Naturforsch. 52b, 391-397. (doi:10.1515/ znb-1997-0315)

64. Howard CJ, Kennedy BJ, Woodward PM. 2003 Ordered double perovskites - a grouptheoretical analysis. Acta Cryst. B 59, 463-471. (doi:10.1107/S0108768103010073) 